\title{
Correction to: Efficiency and safety of renal denervation via cryoablation (Cryo-RDN) in Chinese patients with uncontrolled hypertension: study protocol for a randomized controlled trial
}

\author{
Han Chen ${ }^{1 \dagger}$, Meng Ji ${ }^{1,2+}$, Yi Zhang ${ }^{3+}$, Yawei Xu ${ }^{3}$, Lingjuan Qiao ${ }^{4}$, Li Shen ${ }^{1,5^{*}}$ and Junbo Ge ${ }^{1,5^{*}}$
}

Correction to: Trials (2019) 20:653

https://doi.org/10.1186/s13063-019-3693-9

After publication of our article [1] we were notified that the word "References" was wrongly included in the title.

Originally published title:

- ReferencesEfficiency and safety of renal denervation via cryoablation (Cryo-RDN) in Chinese patients with uncontrolled hypertension: study protocol for a randomized controlled trial

Correct title:

- Efficiency and safety of renal denervation via cryoablation (Cryo-RDN) in Chinese patients with uncontrolled hypertension: study protocol for a randomized controlled trial

The original article has been corrected.

\section{Author details}

'Department of Cardiology, Zhongshan Hospital, Fudan University, Shanghai, China. ${ }^{2}$ Institute of Biomedical Sciences, Fudan University, Shanghai, China. ${ }^{3}$ Department of Cardiology, Shanghai Tenth People's Hospital, Shanghai, China. ${ }^{4}$ CryoFocus MedTech (Shanghai) Co., Ltd., Shanghai, China. ${ }^{5}$ Shanghai Institute of Cardiovascular Diseases, Shanghai, China.
Published online: 27 December 2019

Reference

1. Chen $\mathrm{H}$, et al. Efficiency and safety of renal denervation via cryoablation (Cryo-RDN) in Chinese patients with uncontrolled hypertension: study protocol for a randomized controlled trial. Trials. 2019;20:653. https://doi. org/10.1186/s13063-019-3693-9.

The original article can be found online at https://doi.org/10.1186/s13063019-3693-9

* Correspondence: shen.li1@zs-hospital.sh.cn; ge.junbo2@zs-hospital.sh.cn

${ }^{+}$Han Chen, Meng Ji and Yi Zhang contributed equally to this work.

'Department of Cardiology, Zhongshan Hospital, Fudan University, Shanghai,

China

Full list of author information is available at the end of the article

C The Author(s). 2019 Open Access This article is distributed under the terms of the Creative Commons Attribution 4.0 International License (http://creativecommons.org/licenses/by/4.0/), which permits unrestricted use, distribution, and reproduction in any medium, provided you give appropriate credit to the original author(s) and the source, provide a link to the Creative Commons license, and indicate if changes were made. The Creative Commons Public Domain Dedication waiver (http://creativecommons.org/publicdomain/zero/1.0/) applies to the data made available in this article, unless otherwise stated. 